\title{
DESAIN DAN ANALISA SIMULASI MESIN PNEUMATIC CONVEYING UNTUK MEMINDAHKAN BIJI JAGUNG
}

\author{
Reza Hadi Cahyono \\ Program Studi Teknik Mesin \\ Universitas Muria Kudus \\ Email: rezahadicahyono@gmail.com \\ Masruki Kabib \\ Program Studi Teknik Mesin \\ Universitas Muria Kudus \\ Email: masruki.kabib@umk.ac.id \\ Akhmad Zidni Hudaya \\ Program Studi Teknik Mesin \\ Universitas Muria Kudus \\ Email: akhmad.zidni@umk.ac.id
}

\begin{abstract}
ABSTRAK
Pneumatic Conveying adalah suatu alat transportasi yang berfungsi memindahkan partikel padat dalam suatu aliran fluida. Tujuan dari penelitian ini adalah merancang mesin pneumatic conveying dengan sistem tekanan udara tertutup untuk pengangkut biji jagung dengan kapasitas $200 \mathrm{~kg} / \mathrm{jam}$. Metode dalam desain mesin ini melalui beberapa tahapan, yaitu ; studi literatur, menentukan bahan-bahan yang dipakai, pertimbangan desain, menentukan konsep desain, dan gambar kerja. Hasil penelitian ini adalah menggunakan bahan produksi pemindah partikel biji jagung dengan massa jenis $721 \mathrm{~kg} / \mathrm{m}^{3}$, pipa acrylic bening dua biji diameter 1 inchi dan $3 / 4$ inchi dengan panjang $6000 \mathrm{~mm}$, menggunakan compressor dengan kapasitas udara 457 1/Menit dan daya 170 Watt. Hasil simulasi tegangan pada bagian kekuatan material rangka penopang pipa memperoleh data tegangan dari von misses stress $443.003 \mathrm{Mpa}$, displacement yaitu sebesar $125,108 \mathrm{~mm}$,safety factor $15 \mathrm{Ul}$, dan tegangan principal $461.232 \mathrm{Mpa}$.
\end{abstract}

Kata kunci: Pneumatic Conveying, Udara Tertutup, Biji Jagung.

\begin{abstract}
Pneumatic Conveying is a means of transportation that functions to move solid particles in a fluid flow. The purpose of this research is to design a pneumatic conveying machine with a closed air pressure system for transporting corn kernels with a capacity of $200 \mathrm{~kg} / \mathrm{hour}$. The method in designing this machine goes through several step, including; literature studies, determine the materials used, design considerations, determine design concepts, and work drawings. The results of this study were to use the production material for moving corn seed particles with a density of $721 \mathrm{~kg} / \mathrm{m} 3$, two clear acrylic pipes of 1 inch and 3/4 inch diameter with a length of $6000 \mathrm{~mm}$, the compressor capacity requires air, $457 \mathrm{~L} /$ Minute. and a power of $170 \mathrm{Kw}$, and in the pressure simulation of the strength of the pipe support frame material, the stress data obtained from the von misses stress 443,003 Mpa, displacemen 125,108 mm, $15 \mathrm{Ul}$ safety factor, and the principal stress 461,232 Mpa.
\end{abstract}

Keywords: Pneumatic Conveying, Air Covered, Corn Kernels. 


\section{PENDAHULUAN}

Pneumatic conveying merupakan salah satu alat pemindah material yang cepat dan efisien. Ada dua macam sistem pengangkut material partikel padat, yaitu ; 1.) Sistem tekanan positif adalah jenis paling umum dari sistem konveyor pneumatik yang digunakan. Sistem ini mendorong material yang dikirimkan melalui sistem yang mengeluarkan material pada tekanan atmosfer. Tergantung pada jarak pengangkutan, sistem ini memerlukan tekanan tinggi, karena penting untuk memastikan bahwa sistem dapat mendorong benda padat yang melalui konfigurasi pipa terpanjang. Sistem ini sangat cocok untuk satu lokasi penjemputan dan beberapa lokasi pengumpulan. 2.) Sistem tekanan negatif menggunakan pompa vakum perpindahan positif di hilir sistem pengangkutan untuk menarik material yang dibawa melalui sistem. Ini sangat cocok untuk beberapa lokasi pengambilan dan satu lokasi pengumpulan. Hal ini memungkinkan sistem bebas debu dan bocor [1].

Proses pemindahan material ada permasalahan untuk pemindahan biji jagung yang perlu di atasi untuk menjaga kebersihan dari lingkungan sendiri ataupun dari segi bahan biji jagungnya agar tetap higienis saat di produksi. Ada beberapa jenis alat yang di gunakan, adapun kelebihan dan kelemahannya sebagai berikut ; 1.) Bucket elevator, dengan kelebihan dapat mengangkut bahan dengan kemiringan yang curam, mengangkut material yang cenderung lengket, serta mengangkut bongkahan-bongkahan besar dan material yang berat, harga relatif lebih murah, dan dengan kelemahan bahan yang diangkut kebersihannya tidak terjaga, tidak dapat digunakan jika bahan melalui jalur yang berkelok-kelok. 2.) Van-t belt, dengan kelebihan harga lebih murah, mudah dalam pemasangan, dapat dipakai untuk jarak poros yang jauh, dan dengan kelemahan jika suhu tinggi akan mengalami pemuaian yang menyebabkan kekuatan sabuk (belt) menurun, jika bahan yang dihantarkan berupa serbuk maka serbuk akan masuk ke puli penggerak sehingga slip, sabuk atau belt memerlukan perawatan yang banyak akibat robek dan suhu tinggi. 3.) Conveyor chain, dengan kelebihan kemungkinan terjadi muai panjang akibat suhu tinggi relatif kecil, kemungkinan terjadi slip karena sistem transmisi sangat kecil karena roda transmisi menggunakan sprocket, dan dengan kelemahan memerlukan pelumasan rantai, suara bising. 4.) Pneumatic conveyor, dengan kelebihan bahan yang diangkut kebersihannya tetap terjaga, dapat digunakan jika bahan melalui jalur yang berkelok-kelok, bahan yang diangkut tidak dapat mengalir kembali atau jatuh ke bawah, dengan pemakaian system tekanan udara tertutup, dapat mengangkut biji-bijian berupa jagung dengan tidak mencemari sekitar lingkungan, dan dengan kelemahan hanya dapat mengangkut bahan yang ringan atau berbentuk bongkahan kecil seperti biji-bijian, tidak dapat mengangkut bahan dengan kemiringan yang curam [2] [3].

Pneumatic conveying merupakan alat pemindah material biji jagung yang effisien, higienis, untuk partikel material biji jagung yang system pemindahnya menggunakan tekanan udara tertutup. Pneumatic conveying lebih effisien dan higienis karena dengan system tertutup di dalam pipa tidak akan terjadi pencemaran lingkungan disekitar. Hal ini yang mungkin tidak seperti alat-alat pemindah lainnya. Yang perlu di perhatikan dalam sistem ini adalah kemungkinan terjadinya hambatan pada sistem perpipaan, terutama sekali pada belokan [4]. Sistem pemindahan material dalam bentuk line juga dapat di lakukan dengan menggunakan sistem control, hal ini untuk memastikan tidak terjadinya hambatan selama proses pemindahan [5].

Instalasi sistem pneumatic conveying yang perlu di perhatikan adalah sistem perpipaannya. Sistem ini perlu di dukung oleh rangka dudukan yang kuat. Kekuatan rangka penopang perlu di perhitungan dalam desain [6]. Analisa kekuatan dapat dilakukan menggunakan metode elemen hingga. Analisa di lakukan untuk mendapatkan nilai tegangan pada komponen mesin pemindah material. Analisa ini digunakan untuk mencegah terjadinya kegagalan selama mesin bekerja [7]. Sistem pneumatic conveying perlu memperhitungan tekanan dan aliran udara yang bekerja. Perhitungan pneumatic yang tepat akan mempengaruhi hasil desain dan instalasi pneumatic conveying [8].

Tujuan penelitian ini adalah mendesain mesin pneumatic conveying dengan sistem tekanan udara tertutup untuk pengangkut biji jagung dengan kapasitas $200 \mathrm{~kg} / \mathrm{jam}$. Analisa simulasi dilakukan pada rangka penopang terhadap hasil perhitungan defleksi pada bagian kekuatan material rangka penopang pipa mesin pneumatic conveying, dengan menggunakan metode elemen hingga. 


\section{METODOLOGI PENELITIAN}

Metode penelitian yang di gunakan adalah desain dan simujlasi dengan tahapan sebagaimana ditunjukan pada diagram alir di gambar 1 .

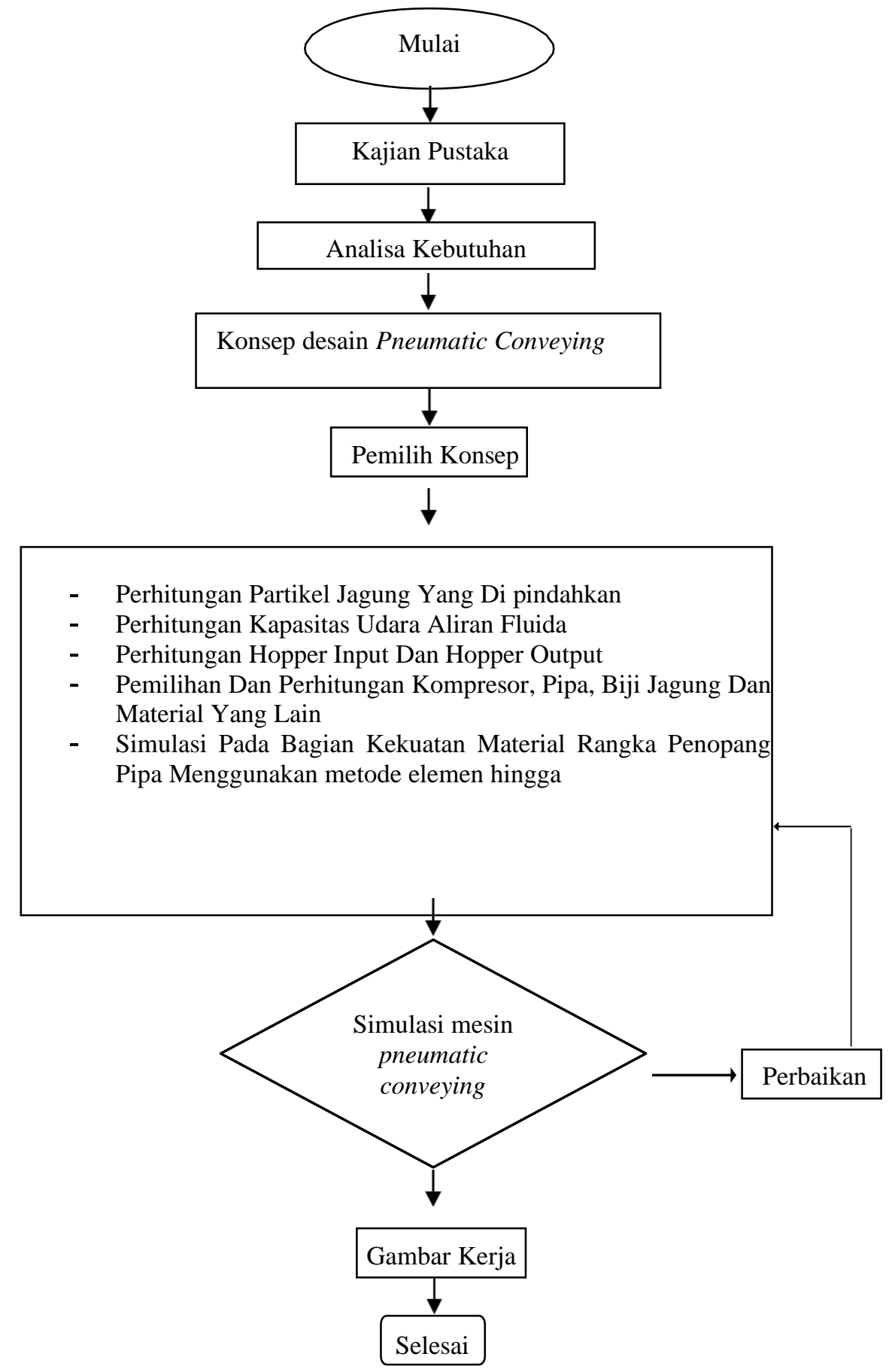

Gambar 1 Diagram alir penelitian 


\section{HASIL DAN PEMBAHASAN}

\subsection{Analisa Kebutuhan Sistem}

a. Aspek Teknik ;

Ukuran pipa saluran udara yang di perlukan $30 \mathrm{~mm}$, kapasitas pengankutan $200 \mathrm{~kg}$ perjam, tekanan udara mampu mendorong biji jagung ke hopper output, sistem pengumpanan menggunakan rotary valve, panjang lintasan pemindahan material $6000 \mathrm{~mm}$, pembangkit udara tekanan menggunakan konpresor.

b. Aspek manufaktur

Penyambungan rangka menggunakan pengelasan, penyambungan pipa menggunakan elbow. Proses manufaktur mudah dilakukan.

c. Aspek Ergonomi

d. Tinggi hopper input dapat di jangkau operator, panel kontrol diletakkan pada posisi mudah di jangkau operator

e. Aspek ekonomi

Biaya pembuatan relatif murah, pembelian komponen mudah di dapatkan.

\subsection{Desain Mesin Pneumatic Conveying}

Desain mesin pneumatic conveying sebagaimana di tunjukkan pada gambar 2.

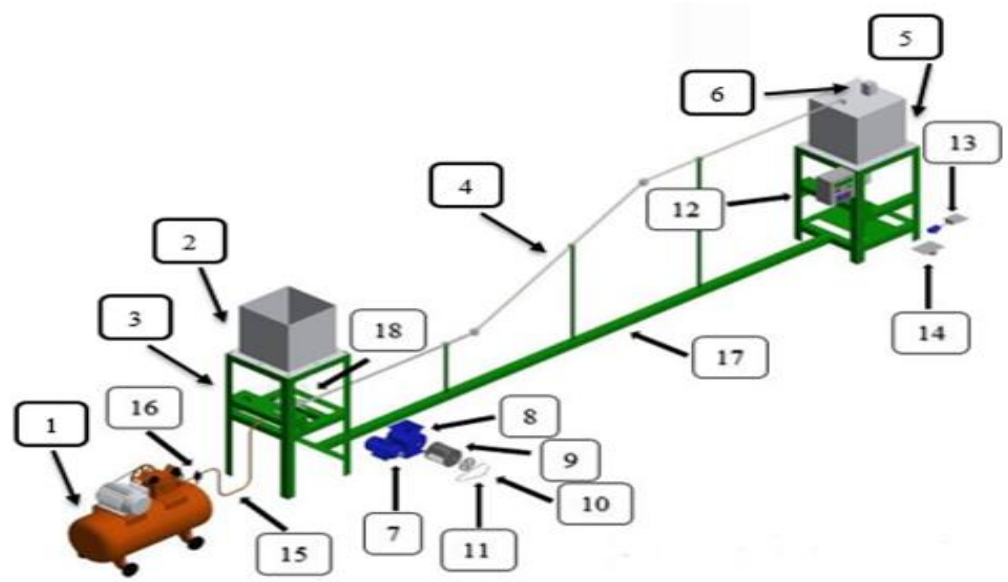

Gambar 2. Desain mesin Pneumatic Conveying

Bgian -bagian mesin pneumatic conveying terdiri dari ::
1. Kompressor
2. Hopper input
3. Rangka
4. Pipa penyalur
5. Hopper output
6. Filter keluaran
7. Motor listrik
8. Body rotary valve
9. Rotor
10. Pulley
11. Sabuk-v
12. Panel control
13. Katup keluaran
14. Loadcell
15. Regulator pressure gauge
16. Selang compressor
17. Penyangga rangka
18. nozzle

Mekanisme kerja mesin pneumatic conveying adalah sebagai berikut :

a) Mesin ini menggunakan udara mampat yang dihasilkan dari kompresor.

b) Biji jagung yang sudah kering dimasukkan ke dalam hopper input ditampung pada hopper input kemudian turun dan diteruskan oleh rotary valve. 
c) Rotary valve digerakkan menggunakan motor listrik yang menggunakan transmisi penghubung sabuk V.

d) Biji jagung yang diteruskan oleh rotary valve kemudian turun menuju pipa penyalur yang di dalamnya terdapat komponen nozzle yang dapat meningkatkan kecepatan aliran fluida saat biji jagung keluar dan lalu ditransfer atau dipindahkan oleh angin dari kompresor menuju hopper output.

e) Biji jagung akan turun ke corong hopper output, dan sisa angin akan keluar dari filter.

f) Biji jagung yang akan keluar sebelumya di program melalui panel control dengan system katup keluaran yang bekerja buka/tutup katup keluaran.

g) Biji jagung yang telah di tampung akan di timbang terlebih dahulu di Loadcell dengan kapasitas pengeluaran maximal $10 \mathrm{~kg}$, yang nantinya di program di panel control.

Spesifikasi dari mesin pneumatic conveying adalah sebagai berikut :

1. Jenis pengangkut

2. Bahan Material Yang diangkut

= pneumatic conveying

3. Panjang lintasan

$=$ jagung $($ biji $)$

4. Tinggi

$=6000 \mathrm{~mm}$

5. Diameter pipa 1.)

$=1,5$ meter

6. Diameter pipa 2.)

$=1 \mathrm{in}$

7. Sytem pembangkit

$=3 / 4$ in

8. Kapasitas pneumatic conveying yang diinginkan $=200 \mathrm{~kg} / \mathrm{jam}$

9. Sistem pembangkit

$=$ kompressor

\subsection{Perhitungan Kapasitas Produksi}

Laju aliran massa (m) yang direncanakan untuk kapasitas produksi $200 \mathrm{~kg} / \mathrm{jam}$. Produk yang di angkut adalah berupa biji jagung dengan kapasitas pemindah dapat di hitung dengan persamaan 1 .

$$
\mathrm{Q}=\dot{\mathrm{m}} \mathrm{xt}
$$

Dimana, $\dot{\mathrm{m}}$ adalah laju aliran massa $(\mathrm{kg} / \mathrm{jam})$ yang direncanakan untuk kapasitas produksi adalah $=$ $200 \mathrm{~kg} / \mathrm{jam}$, dan dengan $\mathrm{t}$ adalah waktu (jam).

\subsection{Menghitung Debit Aliran Partikel Jagung}

Menghitung volume biji-bijian dari rotary valve yang dipindahkan bisa menggunakan persamaan 2 berikut :

$$
\mathrm{Q}=\frac{\dot{\mathrm{m}}}{\rho}
$$

Dimana, $\mathrm{Q}$ adalah debit aliran partikel $\left(\mathrm{m}^{3} / \mathrm{s}\right)$ biji jagung, dengan $\dot{\mathrm{m}}$ adalah laju aliran massa $(\mathrm{kg} / \mathrm{s}), \rho$ adalah massa jenis jagung $\left(\mathrm{kg} / \mathrm{m}^{3}\right)=721 \mathrm{~kg} / \mathrm{m}^{3}$.

\subsection{Menghitung Luas Pipa (A)}

Perhitungan luas pipa dimana yang dilintasi bahan partikel jagung di dalam pipa dengan jarijari 25,4 $\mathrm{mm}=0,0254 \mathrm{~m}$ tersebut menggnakan persamaan 3 .

$$
\mathrm{A}=\frac{\pi}{4} X D^{2}
$$

Dimana, A adalahluas penampang pipa, $\pi$ adalah 3,14, dan $r$ adalah jari-jari. 


\subsection{Menghitung Kecepatan Aliran Partikel Jagung Pada Pipa}

Kecepatan aliran partikel biji jagung pada pipa $\varnothing=25,4 \mathrm{~mm}=0,0254 \mathrm{~m}^{2}$, menggunakan persamaan 4.

$$
\mathrm{V}=\frac{\mathrm{Q}}{\mathrm{A}}
$$

Dimana, V adalah kecepatan aliran (m/s) partikel biji jagung, Q adalah debit aliran $\left(\mathrm{m}^{3} / \mathrm{s}\right)$ partikel biji jagung yang di pindahkan rotary valve, dan A adalah luas penampang $\left(\mathrm{m}^{2}\right)$ pipa.

\subsection{Perhitungan Kapasitas Udara Untuk Memindahkan Jagung}

Fraksi gas di asumsikan untuk mendorong partikel jagung dengan aliran fluida gas solid di dalam pipa sebanyak (asumsi kecepatan udara $4 \mathrm{~m} / \mathrm{s}$ ), dapat di hitung dengan persamaan 5 .

$$
\text { Q : v x Apipa } \mathrm{x} \epsilon
$$

Dimana, Q (debit kapasitas udara), v kecepatan udara (asumsi kecepatan udara $4 \mathrm{~m} / \mathrm{s}$ ), $\mathrm{A}_{\text {pipa }}$ : luas penampang pada pipa, dan $\epsilon$ : Fraksi Gas (75\%).

\subsection{Perhitungan Hopper}

Perhitungan hopper berfungsi untuk menentukan kapasitas bahan yang akan dimasukan kedalam hopper menggunakan persamaan 6.

$$
\mathrm{V}=\mathrm{Q} \times \mathrm{t}
$$

Dimana, Q adalah debit partikel jagung $\left(\mathrm{m}^{3} / \mathrm{s}\right)$, dan T adalah waktu (s).

\subsection{Perhitungan Beban Maksimal Statis}

1. Menghitung massa pipa akrilik dengan diameter $25,4 \mathrm{~mm}$, dan panjang $6000 \mathrm{~mm}$, menggunakan persamaan 7.

$$
(\pi R) \times L x b j a)-(\pi) x L x b j a)
$$

Dimana, $\mathrm{L}$ adalah panjang pipa akrilik (m), $\mathrm{R}$ adalah jari-jari luar pipa akrilik (m), $\mathrm{r}$ adalah jari-jari dalam pipa akrilik (m), bja berat jenis akrilik $\left(\mathrm{kg} / \mathrm{m}^{3}\right) 1180 \mathrm{~kg} / \mathrm{m}^{3}$.

2. Menghitung massa partikel jagung mengisi penuh dalam pipa akrilik menggunakan persamaan 8

$$
\mathrm{V}=\pi \times \mathrm{r}^{2} \times \mathrm{L}
$$

Dimana, (r) adalah diameter dalam (cm), dan (L) adalah panjang pipa akrilik (cm).

\subsection{Simulasi Rangka Penopang Pipa}

Setelah dilakukan perhitungan secara teoritis lalu melakukan simulasi untuk rangka penopang pipa dengan memberikan Gaya beban $1371.000 \mathrm{~N}$ pada luas penampang rangka penopang pipa dengan material baja hollow $(30 \times 30 \times 1,9 \mathrm{~mm})$, lalu mendapatkan fixture pada rangka penopang pipa dalam aplikasiannya. Dari simulasi tegangan pada rangka penopang pipa yang menggunakan von mises, didapatkan hasil momen bending maksimal 443.003 Mpa. Sebagaimana di tunjukkan pada gambar 3 . 


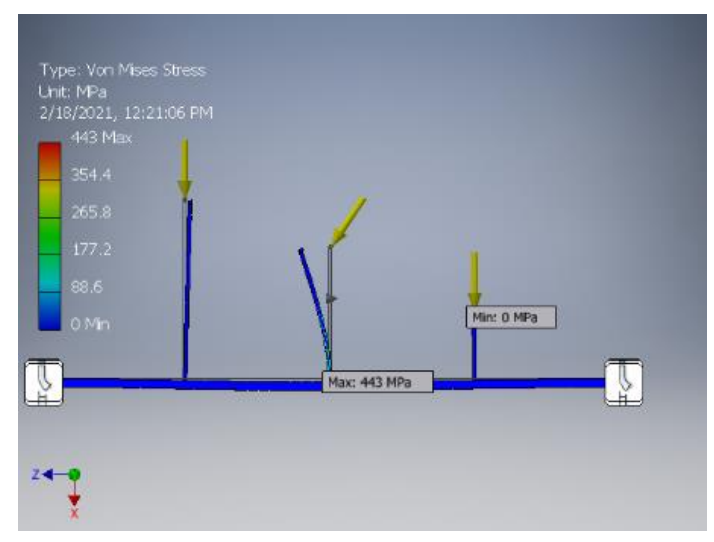

Gambar 3. hasil simulasi tegangan von mises

Dengan kondisi pembebanan yang sama yaitu $1371 \mathrm{~N}$, kemudian didapat nilai maksimal displacement yatitu sebesar 125,108 mm, sebagaimana di tunjukkan pada gambar 4 .

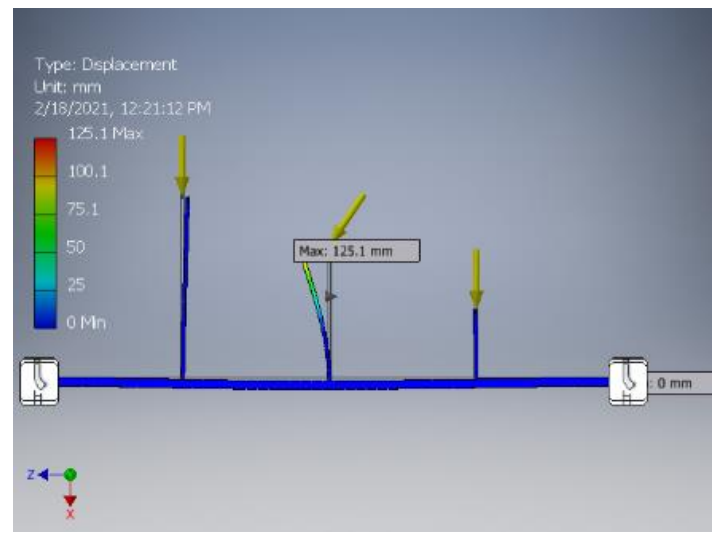

Gambar 4. simulasi maksimal displacement

Simulasi pada rangka penopang pipa ini diperoleh faktor keamanan sebesar $15 \mathrm{ul}$, dengan nilai yang disyaratkan yaitu 3, maka perancangan pada komponen rangka penopang pipa ini bisa dikatakan aman, sebagaimana ditunjukkan pada gambar 5.

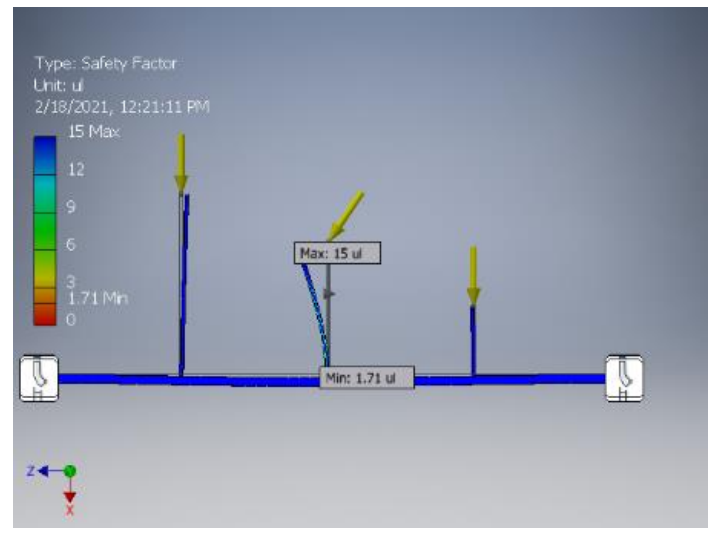

Gambar 3.4 hasil simulasi faktor keamanan 


\subsection{Simulasi Tegangan Utama Pada Rangka Penopang Pipa}

Simulasi tegangan principal pada rangka penopang pipa dilakukan dengan memberi gaya tekan sebesar 1371.000 N. Didapatkan hasil tegangan maksimal 461.232 Mpa yang terjadi pada pada rangka penopang pipa.

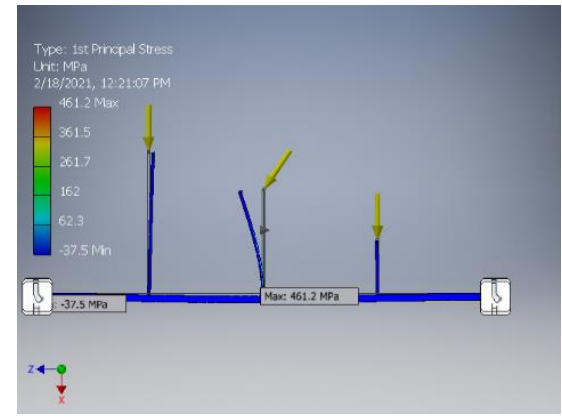

Gambar 3.5 hasil simulasi tegangan principal stress

\section{KESIMPULAN}

Hasil penelitian ini mendapatkan desain mesin pneumatic conveying dengan kapasitas pemindahan material $200 \mathrm{~kg}$ perjam, dengan kapasitas udara 457 liter permenit, dan daya kompresor 170 Watt. Hasil simulasi tegangn von mises adalah 443,003 Mpa, displacement yatitu sebesar $125,108 \mathrm{~mm}$, dan menggunakan safety factor sebesar $15 \mathrm{ul}$, maka perancangan pada komponen rangka penopang pipa ini bisa dikatakan aman. Simulasi tegangan utama pada rangka penopang pipa didapatkan hasil tegangan maksimal 461,232 Mpa yang terjadi pada pada rangka penopang pipa.

\section{DAFTAR PUSTAKA}

[1] Amalia, R. (2014). Unit operasi I: Proses Mekanik Pneumatic Conveying Disusun oleh: Kelompok 2 Dinda Labibah Ubay Farel Abdala Shiddiq Louis Claudia Marpaung. (21030113130201), 1-16.

[2] Faisal Yanuar Adiba. (2016). Pemilihan Kompresor Pada Instalasi Udara Bertekanan Sistem Pneumatik Hidrolik Di Pressure Tank Line Indoor PT. PJB Unit Pembangkit Brantas.

[3] Joshua Walker, Taimoor Asim, Rakhes Mishra, Martin Adam, 2016, Life-Cycle Cost Modelling of Pneumatic Conveying Pipelines for the Lean Phase Transport Condition, Proceedings of the 6thInternational and 43rdNational Conference on Fluid Mechanics and Fluid Power, December 15-17, 2016, MNNITA, Allahabad, U.P., India

[4] M Sholikhudin Zuhdi 21131050 35. (2017). Simulasi Numerik Pada Dense Phase Pneumatic Conveyor Dengan Variasi Sudut Pressurrized Air Assisted 45o dan 90o Dan R/D 1 , 1,5 , 2 Pada Elbow Vertikal Untuk Mereduksi Terjadinya Clogged Pada Sistem Perpipaan.

[5] S. Huda, M. Kabib, R. Winarso, 2017, Desain Automatic Line Plastic Packing of Cake Berbasis Mikrokontroler ATMEGA 328, seminar SNTAIF ke 3, 17 Juli 2017, pp. 577-584.

[6] Prasetyo, B. (2012) Rancang Bangun Rangka Mesin Pencacah Plastik Kemasan. Universitas Sebelas Maret.

[7] A. Rofeg, M. Kabib, 2018, Analisa Tegangan Screw Conveyor Pada Mesin Pencampur Garam Dan Iodium Sesuai SNI 3556 Dengan Metode Elemen Hingga, Jurnal Simetris . Teknik Mesin, Elektro dan Ilmu Komputer., vol. 9, no. 2, pp. 935-940, doi: 10.24176/simet.v9i2.2452.

[8] R. F. Indrianto, M. Kabib, R. Winarso, 2018, Rancang Bangun Sistem Pengepresan Dengan Penggerak Pneumatik Pada Mesin Press Dan Potong Untuk Pembuatan Kantong Plastik Ukuran 400 X 550 mm, Jurnal Simetris P-ISSN: 2252-4983, E-ISSN: 2549-3108, volume 9, No. 2, pp 1053-1060. 